PontIFícIa UNIVERSIDADE CATÓLICA dO RIO DE JANEIRO

\title{
Percepção do Consumidor Sobre Aplicativos de Transporte Particular e Táxis
}

\author{
Nikolas Michahelles
}

Trabalho de Conclusão de Curso

Centro de ciênCIAS SOCIAIS - CCS

DePARTAMENTO de AdMINISTRAÇÃo

Graduação em Administração de Empresas 
Nikolas Michahelles

Percepção do Consumidor Sobre Aplicativos de Transporte Particular e Táxis

Trabalho de Conclusão de Curso

Trabalho de Conclusão de Curso, apresentado ao programa de graduação em Administração da PUC-Rio como requisito parcial para a obtenção do título de graduação em Administração.

Orientador(a): Marcela Amorim

Rio de Janeiro, Novembro de 2018. 


\title{
Resumo
}

Michahelles, Nikolas. Percepção dos consumidores sobre os transportes com motoristas particulares por aplicativos e os táxis. Rio de Janeiro, 2018. Trabalho de Conclusão de Curso - Departamento de Administração. Pontifícia Universidade Católica do Rio de Janeiro.

Por esse trabalho se analisará o ponto de vista do consumidor sobre o uso dos aplicativos de transporte em veículos particulares com motoristas e os táxis comuns de rua. Terá a tentativa de entender o motivo da forte adesão dos consumidores e a aparente preferência pelo uso dos aplicativos ao invés dos táxis de rua. Tratará dos principais pontos no serviço de ambos os meios para uma comparação ser feita e entendermos os motivos e motivações da escolha por um ou pelo outro.

\section{Palavras-chave}

Percepção do consumidor, comportamento, motivação, aplicativo e táxi

\begin{abstract}
Michahelles, Nikolas. The perception of general users upon personal transportation with drivers apps and the common street taxi. Rio de Janeiro. Rio de Janeiro, 2018. 40p. Undergraduate thesis - Business Department. Pontifícia Catholic School of Rio de Janeiro.

In this therm we will examine the main motivations that users have in the so called transport apps, and make a comparative with thecommon street taxis. It will also address consumer habits of purchase, motivations and points of interests.
\end{abstract}

\section{Key-words}

Consumer perception, behaviour, motivataion, apps and taxi. 


\section{Sumário}

1. O tema e o problema de estudo 1

1.1. Introdução ao tema e ao problema do estudo 1

1.2. Objetivo do estudo 2

1.3. Objetivos intermediários do estudo 3

1.4. Delimitação e foco do estudo 3

1.5. Justificativa e relevância do estudo 3

2. Revisão de literatura 4

2.1. O comportamento do consumidor 4

2.2. Tomada de decisão cognitiva 5

2.3. Percepção 6

3 . Metodologia de coleta e análise de dados do estudo 8

3.1. Método de pesquisa utilizado 8

3.2. Fontes de informação selecionadas para a coleta de dados do estudo 9

3.3. Procedimentos e instrumentos de coleta de dados do estudo 9

$\begin{array}{lr}\text { 3.4. Análise } & 10\end{array}$

4. Resultado e Análise 11

4.1. Descrição da amostra do perfil dos entrevistados 11

$\begin{array}{ll}\text { 4.2. Descrição e análise dos resultados } & 13\end{array}$

5. Conclusão 24

6. Referências Bibliográficas 26

7. Anexo 29 


\section{Lista de Gráficos}

Gráfico 1: Aplicativos no Brasil (Fonte: IBOPE, 2017) .................................... 1

Gráfico 2: Gênero dos entrevistados (FONTE: Google Forms) .......................... 12

Gráfico 4: Renda Mensal dos entrevistados (FONTE: Google Forms) ............. 12

Gráfico 3: Idade dos entrevistados (FONTE: Google Forms) ......................... 12

Gráfico 5: Principais meios de transportes utilizados (FONTE: Google Forms) .... 13

Gráfico 6: Principais aplicativos de transportes utilizados (FONTE: Google Forms)

Gráfico 7: Frequência de uso de aplicativos com motorista particular (FONTE: Google Forms)............................................................................... 15

Gráfico 8: Frequência de uso de táxis (FONTE: Google Forms) ......................... 16

Gráfico 9: Fatores positivos no uso de táxis (FONTE: Google Forms) …............. 17

Gráfico 10: Fatores positivos no uso de transporte por meio de aplicativos (FONTE:

Google Forms) ........................................................................ 17

Gráfico 11: Motivos que te levam a usar táxi (FONTE: Google Forms) ............... 18

Gráfico 12: Comparação dos serviços oferecidos por táxis e aplicativos (FONTE:

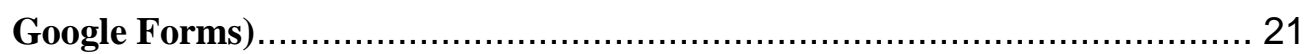

Gráfico 13: Grau de satisfação do consumidor (FONTE: Google Forms)............. 22

Gráfico 14: Número de corridas por mês (FONTE: Exame, 2017) ....................... 22 


\section{O tema e o problema de estudo}

\subsection{Introdução ao tema e ao problema do estudo}

O mercado de serviço de transporte particular atualmente movimenta cerca de $R \$$ 10 milhões por dia no conjunto dos estados de São Paulo e Rio de Janeiro, sendo esses os principais estados a utilizar esse tipo de serviço (FURQUIM, 2017). De acordo com uma pesquisa feita pelo Instituto de pesquisa INSPER, no estado do Rio de Janeiro existem 38 mil taxistas cadastrados pela prefeitura e 50 mil motoristas cadastrados que prestam serviço por transporte fazendo o uso de aplicativos móveis.

Atualmente no Brasil o principal aplicativo de transporte utilizado é a Uber com $54 \%$ do mercado nacional, depois a 99 táxis com 12\% e a Cabify com 4\% (IBOPE, 2017) e $43 \%$ dos entrevistados declararam não fazer uso de aplicativos de transporte.

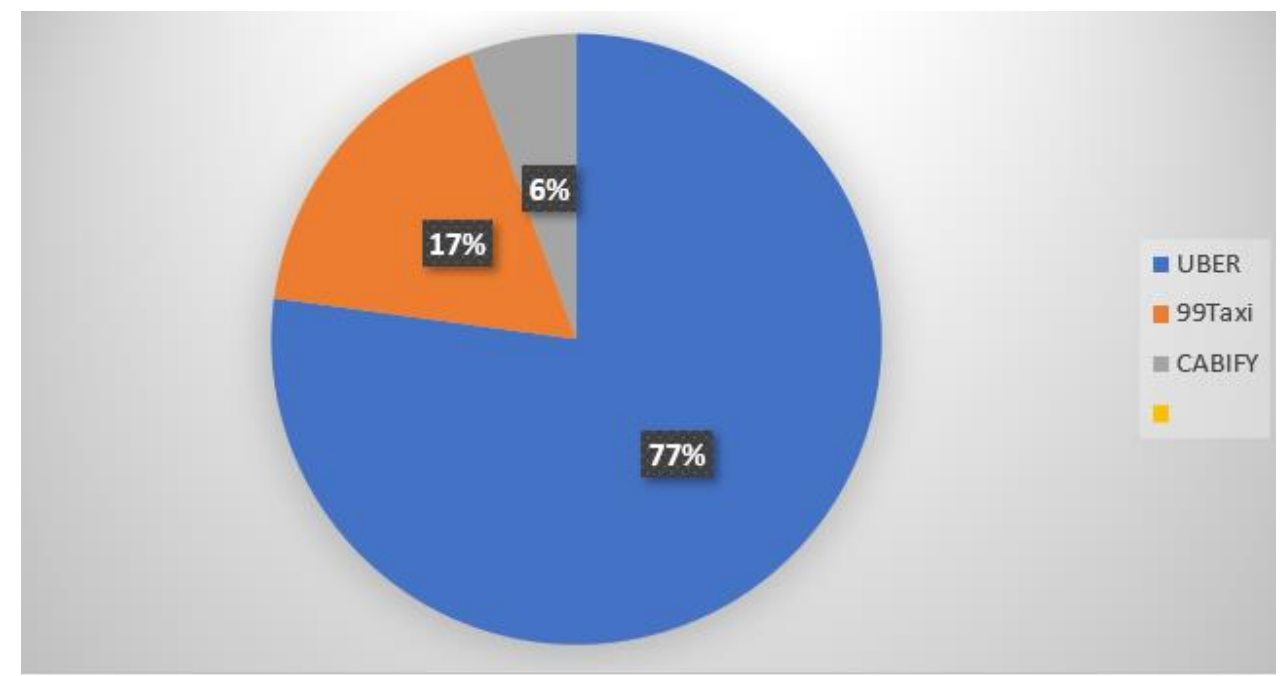

Gráfico 1: Aplicativos no Brasil (Fonte: IBOPE, 2017)

Com a evolução das tecnologias móveis, o consumidor passa a ter mais poder de decisão em relação a quando e onde adquirir os seus produtos ou serviços (DICKINSON, 2015). Sendo assim, os aplicativos de transportes inovaram apresentando uma maneira mais clara, segura e com maior facilidade de pagamento 
para o cliente (SCHAUS, 2015), mostrando uma crescente demanda devido ao engarrafamento e falta de estacionamentos nos perímetros urbanos das capitais (FURQUIM, 2017).

O termo técnico correto para o modelo de transporte utilizando aplicativos móveis é "e-hailing", a partir desse conceito a busca por motoristas é feita baseada na localização do cliente. Permitindo a qualquer pessoa com carteira de motorista de se registrar como motorista, não necessitando de um cadastro na prefeitura ou governo local, apenas cumprindo os pré-requisitos da empresa de "e-hailing" contratante.

Devido a esse crescente consumo é necessário que por parte das empresas presentes no setor de transportes privados de passageiros, entendam o comportamento dos seus consumidores nos dias atuais e para garantir o futuro próspero no mercado nacional. Este estudo terá como foco as cidades do Rio de Janeiro, Porto Alegre, São Paulo e Belo Horizonte.
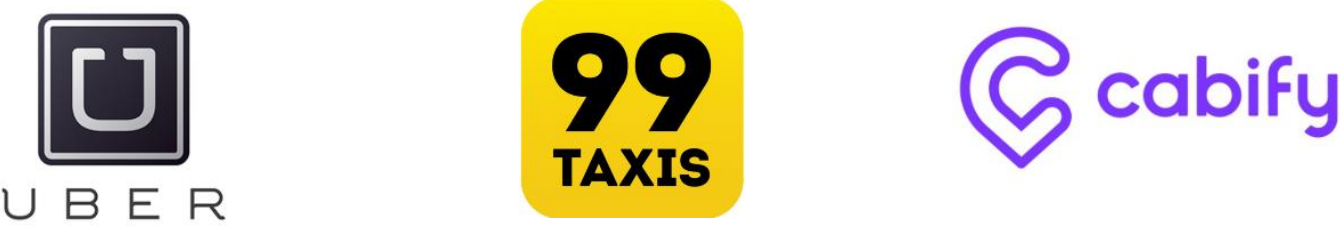

\subsection{Objetivo do estudo}

O seguinte trabalho tem como objetivo identificar quais são os principais fatores que influenciam o consumidor a optar pelo uso de transporte privado por aplicativos ou taxis. 


\subsection{Objetivos intermediários do estudo}

Para se alcançar o objetivo final desse estudo, seguem os objetivos intermediários definidos:

$>$ Identificar as maiores inseguranças dos consumidores ao fazerem o uso dos aplicativos e táxis.

$>$ Compreender o nível de satisfação dos usuários em ambos os casos.

\subsection{Delimitação e foco do estudo}

Este trabalho possui como foco os consumidores de transporte por aplicativos e taxis na cidade do Rio de Janeiro, São Paulo, Belo Horizonte e Porto Alegre. Atualmente não se encontram muitos estudos explorando os principais pontos que determinam a escolha do cliente entre ambos os modelos de transportes.

\subsection{Justificativa e relevância do estudo}

As informações apresentadas neste estudo procuram beneficiar empresários já atuantes nos ramos de taxis urbanos, transportes de e-hailing e as startups ${ }^{1}$ recentes ou ainda em fase de planejamento a compreender melhor o seu consumidor pelas conclusões aqui apresentadas. Também entender o que os atuais clientes percebem como os maiores problemas de ambos os meios de transporte, e o que os consumidores terão como preferência no futuro. Ajudando assim as empresas a entenderem em quais atributos devem focar para aumentarem sua participação e permanência no mercado.

\footnotetext{
${ }^{1}$ O termo "startup" é normalmente relacionado a empresas que estão no começo de suas atividades, muitas vezes ainda não gerando lucro, e relacionadas a inovações em um mercado.
} 


\section{Revisão de literatura}

Neste capítulo são apresentados e discutidos aspectos conceituais e estudos relacionados ao tema que servirão de base para a análise realizada.

Esse capítulo do estudo está sendo dividido em três partes. A primeira aborda o comportamento do consumidor em relação aos serviços de transporte e suas percepções do mesmo.

E na segunda seção é discutido como são feitas as tomadas de decisões dos consumidores no contexto dos serviços.

Em seguida, na terceira seção, será analisado a percepção do consumidor sobre o mercado de transporte por aplicativos, analisando os principais produtos deste mercado e como foi a aceitação da população.

\subsection{0 comportamento do consumidor}

O comportamento do consumidor "é o estudo dos processos envolvidos quando indivíduos ou grupos selecionam, compram, usam ou descartam produtos, serviços, ideias ou experiências para satisfazerem necessidades e desejos" (SOLOMON, 2016).

Segundo Schiffman e Kanuk (2000), a melhor maneira de garantir a melhor lucratividade e ascensão da empresa em um ambiente competitivo é garantir que as necessidades dos seus consumidores sejam supridas. No caso, a habilidade que uma empresa tem de identificar tais necessidades e conseguir se modificar para atendê-las, é o que diferencia as empresas presentes no mercado competidor e garante a sua sobrevivência.

Solomon (2016) descreve as etapas de compras dos consumidores como um processo contínuo e não se limitando apenas ao momento em que é feito o pagamento pelo serviço. O consumidor procura a satisfação esperada do produto após sua compra e o produto deve corresponder a função pretendida.

Sempre que se pensa em consumidor tem que ter em mente quais são suas necessidades. Uma pesquisa desenvolvida pelo psicólogo Henry Murray, indica as três principais necessidades relevantes ao comportamento do consumidor, são elas: Necessidade de afiliação, necessidade de poder e necessidade de singularidade (SOLOMON, 2016). Abrangendo essa parte do estudo, a necessidade de poder é 
essencial ser compreendida. O crescente uso da tecnologia influencia o comportamento dos consumidores diretamente, dando lhes maior poder de decisão sobre as empresas. Segundo dados da 28 ${ }^{\text {a }}$ Pesquisa Anual de Administração e Uso de Tecnologia da Informação nas Empresas, realizada pela Fundação Getúlio Vargas de São Paulo (FGVSP), foram registrados 208 milhões de smartphones no Brasil no ano de 2017. Com um crescimento de $17 \%$ em relação ao mesmo período do ano 2016 , e é previsto um crescimento de $19 \%$ para os próximos dois anos.

A evolução das tecnologias permite ao consumidor decidir quando e como irá consumir o serviço ou produto, assim obtendo um empoderamento maior sobre as empresas atuantes, neste caso, no mercado de transporte urbano particular por aplicativos. Os clientes passam a ter controle sobre a empresa ofertante do produto, podendo cancelar o seu pedido de transporte e direcionar exatamente o destino final sem ter que comunicar ao motorista. (SOLOMON, 2016).

\subsection{Tomada de decisão do consumidor}

A tomada de decisão pode ser abordada de acordo com a perspectiva de processamento de informações, e será analisada por esse método a seguir no setor de serviços.

Os consumidores procuram basear suas decisões com cuidado e calma e relacionando o máximo de informações que eles já possuem sobre o produto, analisando os pontos positivos e negativos de cada serviço disponível, assim tomando a decisão mais satisfatória a eles (SOLOMON, 2016).

Para Churchill e Peter (2007) o reconhecimento de uma nova oportunidade pelos clientes pode ser de fatores internos ou externos, como respectivamente, o sentimento de sede ou um anúncio na televisão. Durante a primeira etapa do processo de compra o consumidor pode reconhecer uma nova necessidade de produto ou reconhecer uma nova oportunidade no mercado no qual deseja adquirir algo (SOLOMON, 2016). Nesse caso podemos comparar o surgimento dos aplicativos de transportes como Uber, 99Taxi e Cabify com os taxis. O mesmo serviço sendo prestado, porém, por um meio diferente que seria por um aplicativo no celular.

Após o reconhecimento do problema o consumidor procura informações no ambiente para tomar uma decisão sensata, seja por uma pesquisa interna em sua memória, ou, na maioria dos casos, em meios externos como propagandas, internet e amigos (Solomon, 2016). No caso dos aplicativos, o consumidor passa a ser altamente atingido por propagandas através de meios diretos como redes sociais e mensagens. 
A terceira etapa envolve em avaliar as alternativas disponíveis para as tomadas de decisões. O consumidor sempre procura recursos e atributos que lhe são importantes para atender as suas necessidades (CHURCHILL e PETER, 2007). As pessoas costumam ter um conjunto evocado de empresas em sua mente, nos casos mais comuns não passam de três opções nas quais ele tem conhecimento prévio sem nem mesmo conhecer do produto ofertado (SOLOMON, 2016). Atualmente o consumidor brasileiro se depara com três principais marcas que dominam o mercado, são elas em ordem de grandeza no país: Uber, 99taxi e Cabify (IBOPE, 2017).

No período de escolha do produto o consumidor já analisou as informações disponíveis entre as empresas pesquisadas e toma a decisão de consumo (CHURCHILL e PETER, 2007). Apesar de pensarmos que quanto mais recursos de um produto seria melhor, não, pesquisas demonstram que a maioria das devoluções de produtos da Philips Eletronics são pôr os clientes não saberem como usá-los. Em muitos casos a simplicidade de um novo produto pode ser uma vantagem competitiva atualmente (SOLOMON, 2016). Entre os aplicativos para transporte individual e táxis, o consumidor irá fazer a escolha do meio que Ihe trará um maior benefício em função da necessidade que se faz presente naquele momento de consumo.

$\mathrm{Na}$ última etapa temos a avaliação pós compra, os consumidores avaliam se os serviços ou produtos atenderam as suas expectativas ou não. Segundo Kotler (2006) a satisfação é mensurada pela proximidade entre o esperado pelo cliente e o recebido na conclusão do uso. Essa etapa determina se o cliente retornará a utilizar o produto ou serviço prestado ou não. Utilizando os aplicativos de transporte como Uber, Cabify e 99taxi, o cliente é direcionada a avaliação da sua corrida. Assim, o usuário tem poder de avaliar o motorista, deixar um comentário e sua nota final do serviço como um todo. Esse é um método onde grande parte do controle de qualidade fica a critério dos consumidores.

\subsection{Percepção}

Cada indivíduo está sujeito a uma visão diferente ou distorcida sobre o mesmo estímulo e podem ter diferentes interpretações (Schiffman e Kanuk, 2000). Cada pessoa seleciona, organiza e interpreta informações de diferentes maneiras, mas principalmente de acordo com experiências passadas e emoções recentes podem modificar a percepção de um produto ou serviço. Segundo Solomon (2002) o significado de um estímulo exercido por um serviço é interpretado pelo indivíduo que está sobre influência de concepções, necessidade e experiências únicas. 
De acordo com Solomon (2002) os consumidores são mais suscetíveis a se interessarem por produtos que lhes chamem a atenção, como por seus atributos físicos, novos desenhos e pela exposição da marca. Os consumidores deixam de perceber estímulos comuns, fazendo com que o marketing tenha que utilizar técnicas como cores fortes, sons e até cheiros para captar novas sensações e gerar uma boa percepção sobra a sua marca (Solomon, 2002).

Os aplicativos móveis de transporte com motoristas privados entraram no mercado em 2014, oferecendo um melhor atendimento, veículos mais luxuosos, um sistema de pagamento diretamente online, sem deixa o cliente frustrado por talvez 0 motorista não ter troco ou o consumidor estar na rua sem notas físicas. E pequenos detalhes que fizeram o marco nos aplicativos, como a oferta de água nos veículos, balas e wifi. Os usuários de transporte por veículos acabam percebendo esses novos atributos como positivos e voltam a reutilizar esse mesmo, sempre gerando uma expectativa de melhoria, como aconteceu pela primeira reação ao poder usar o serviço por aplicativos (Solomon, 2002).

A padronização dos serviços de melhor qualidade feitos pelos aplicativos de transporte, fez com que o conjunto de associações ligadas à marca dos aplicativos ficasse na memória dos consumidores como superiores aos praticados pelos táxis (Schiffman e Kanuk, 2000). 


\section{Metodologia de coleta e análise de dados do estudo}

A partir de agora se faz necessário entender a metodologia utilizada para a pesquisa do estudo e sua lógica por trás de cada tópico do estudo. Após estudar diversos artigos a respeito dos serviços de transportes por aplicativo disponíveis e temas relacionados aos seus respectivos usuários, foi possível elaborar a pesquisa para coleta de opinião dos consumidores. O capítulo está dividido em 4 etapas seguidas na sequência: o método da pesquisa utilizado, as fontes de informação selecionados para coleta de dados, os procedimentos para a coleta de dados e o seu meio de difusão da pesquisa e por fim a análise dos dados coletados. Assim será distribuído o capítulo seguinte. Complementando com as respectivas justificativas para os procedimentos da pesquisa terem sido feitas desta forma e como foi imposto nos resultados apresentados abaixo.

\subsection{Método de pesquisa utilizado}

Neste caso foi utilizado o método de pesquisa quantitativo, que, segundo Fonseca (2007), o principal foco é na objetividade, facilidade de resposta pelo consumidor, e a análise por base de dados é um meio matemático e facilita o cruzamento de informações para a chegada de uma conclusão provável do problema.

Pelo meio de um questionário online feito no "Google Forms"2 foram elaboradas perguntas para compreender a percepção do consumidor sobre os aplicativos com motoristas particulares e os táxis comuns captados nas ruas. $O$ foco foi em entender as principais reclamações dos consumidores em ambos os meios de transportes. Inicialmente foram feitas perguntas de características como idade, sexo e renda mensal para se obter dados básicos dos respondentes da pesquisa.

2 O termo "Google Forms" é um serviço da plataforma Google para a criação de questionários diversos online, mensurar os resultados e facilitar a distribuição do mesmo. 


\subsection{Fontes de informação selecionadas para a coleta de dados do estudo}

O levantamento de dados a ser feito pelo questionário será de caráter primário tendo como base os respondentes das cidades do Rio de Janeiro, Porto Alegre, São Paulo e Belo Horizonte. Todos os entrevistados que já tiverem andado de Táxi ou/e usado transporte com motorista particular por aplicativo estão aptos a responderem o questionário. As perguntas são fechadas com opção de "outros", caso o respondente queira cadastrar outra resposta. Foi escolhida essa fonte por trazer novos dados do mercado, com qualidade, fontes confiáveis e boa precisão das informações colhidas.

A amostra para essa pesquisa foi de 102 pessoas. Conseguimos alcançar uma análise satisfatória em relação à percepção do consumidor e concluir de forma conclusiva a respeito da população utilizada na pesquisa. Para a análise não serão usados dados secundários devido a pouco informação confiável disponível.

Inicialmente as três primeiras perguntas têm caráter de filtragem e mapeamento do respondente. Sendo elas para mapear a idade do respondente, gênero e nível socioeconômico. Assim na análise dos dados tem-se uma base de quem foram os respondentes, pois esta variação pode influenciar os resultados obtidos.

\subsection{Procedimentos e instrumentos de coleta de dados do estudo}

A pesquisa foi elaborada pelo site Google Forms no qual os procedimentos para criação são de fácil manuseio e pelo fato que o link criado no site pode ser facilmente divulgado, pode se verificar no questionário em anexo.

Dentre os meios de disseminação do questionário foram definidas duas frentes para divulgação: Whatsapp e Facebook. Esses meios de divulgação foram escolhidos por obterem uma boa eficácia de resposta as pessoas enviadas. Em ambos os meios, foram enviados o mesmo link para acesso e ficou disponível pelo período de cinco dias, do dia 21 de outubro até o dia 25 de outubro.

Pelo aplicativo Whatsapp o link foi enviado por uma corrente selecionando todos os contatos, com uma mensagem padrão explicando o motivo da pesquisa, o objetivo e agradecendo aos participantes pela atenção. Na mídia social Facebook foram feitos três tipos de divulgação: em grupos da Puc Rio, por mensagem para pessoas individuais e um post no mural. Ambos os meios foram eficazes, mas o retorno pelo Facebook foi maior devido ao maior alcance, e essa taxa pode ser verificada pois o link foi divulgado em diferentes momentos entre ambos os meios. 
Os dois meios utilizados funcionam por uma rede de conhecidos e contatos de primeiro ou segundo grau de separação ligados ao pesquisador. Isso influenciou diretamente os resultados, o número de participantes envolvidos, faixa de renda mensal e faixa etária. A análise será feita no capítulo seguinte com mais detalhes, onde são representados os resultados de cada uma das perguntas utilizadas no questionário.

\subsection{Análise}

O site utilizado Google Forms permite uma análise dos dados aferidos pelo questionário diretamente em seu sistema ou pode ser criada uma planilha em Excelpelo mesmo software, vinculado aos mesmos resultados da plataforma. Apesar da plataforma já gerar gráficos automaticamente, pelos dados trazidos para o Excel consegue-se trabalhar e cruzar informações para chegar a um resultado mais claro e conclusivo.

Os relatórios e gráficos de cada questão serão apresentados e analisados no capítulo a seguir individualmente. Para garantir a consistência e lógica do estudo dos resultados a seguir, tentou-se representar a revisão de literatura apresentada no segundo capítulo. 


\section{Resultado e Análise}

Neste capítulo serão analisadas as respostas obtidas pelo questionário de maneira gráfica e sintetizada. Os dados obtidos por cada pergunta do questionário serão utilizados para cruzar as informações e verificar os principais motivos que levam o consumidor a optar pelo serviço de transportes com motoristas particulares por aplicativo ou táxis.

O capítulo se encontra dividido em duas seções, a primeira se reflete a questões mapeamento e filtragem dos respondentes descrevendo o perfil dos mesmos. $\mathrm{Na}$ segunda seção tem-se as questões relacionadas aos meios de transporte estudados na pesquisa e suas respectivas análises.

\subsection{Descrição da amostra do perfil dos entrevistados}

Nesta amostra foram analisadas 103 pessoas, dentre elas $58,4 \%$ são do sexo feminino e $41,6 \%$ do sexo masculino. A maior parte dos entrevistados foi do gênero feminino, mas para esta pesquisa a diferença não foi significativa. Em sua grande maioria $52,4 \%$ dos participantes foram na faixa etária entre 18 e 25 anos e a segunda maior parte ficaram entre 26 e 33 anos. Isso se deve a rede de conexões do pesquisador. Sendo assim, as duas principais subamostras foram na faixa de renda mensal dois e quatro salários mínimos, e a segunda maior parcela com a renda mensal maior que dez salários mínimos. Ambas a renda e a idade podem influenciar nos resultados devido a classe social que os participantes se encontram e seus costumes de uso com cartões de créditos e tecnologias de aplicativos. A relação dos gráficos relacionadas a esses quesitos estão apresentados a seguir. 


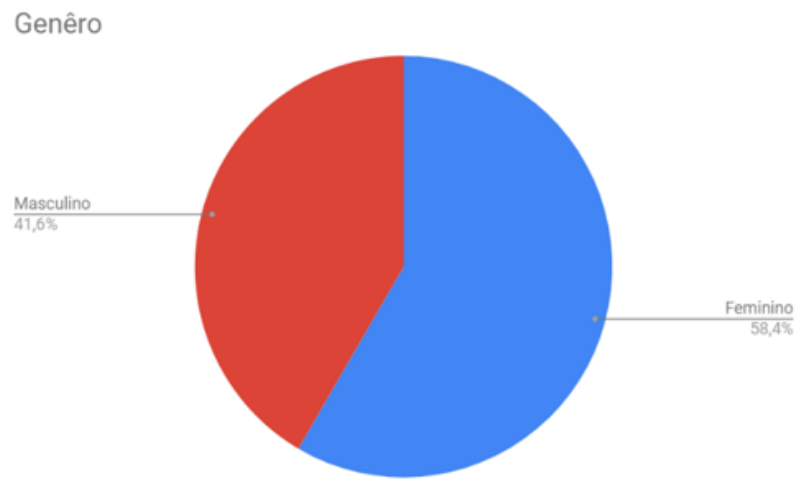

Gráfico 1

Gráfico 2: Gênero dos entrevistados (FONTE: Google Forms)

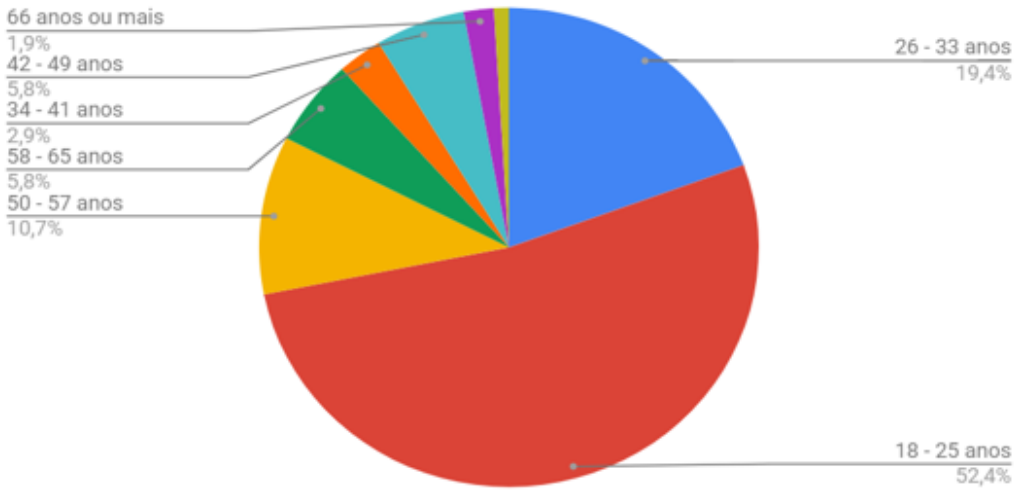

Gráfico 2: Faixa etária

Gráfico 3: Idade dos entrevistados (FONTE: Google Forms)

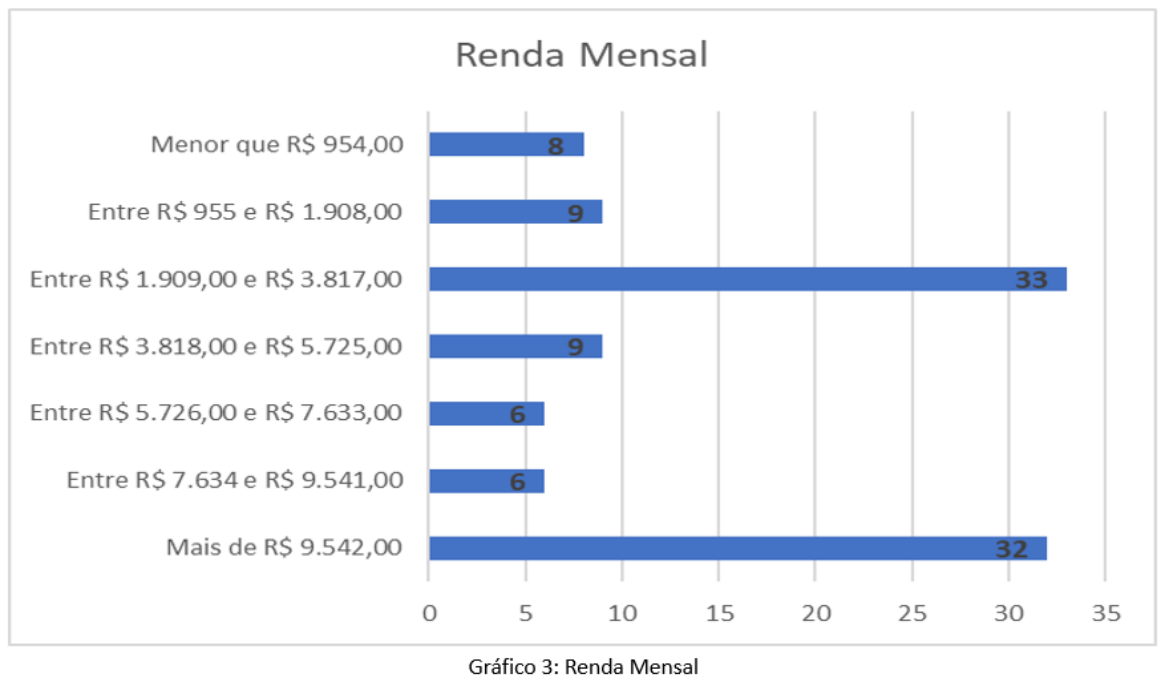

Gráfico 4: Renda Mensal dos entrevistados (FONTE: Google Forms) 


\subsection{Descrição e análise dos resultados}

Nesta primeira questão o intuito foi entender como os respondentes se locomovem em suas rotinas e verificar se o transporte por aplicativo ou táxi estaria sendo utilizado. Analizou-se que $75 \%$ da amostra tem como principal meio de transporte os transportes com motoristas particulares por aplicativos como Uber, Cabify e 99taxis. Em seguida são utilizados os transportes por veículo próprio com $55,3 \%$ e transportes públicos com $51,5 \%$. Nos demais meios de locomoção como: a pé, carona, bicicleta e táxi, foram pouco significantes. Verificamos que a parcela de entrevistados que utilizam Táxis como principal meio é de apenas 16,5\%.

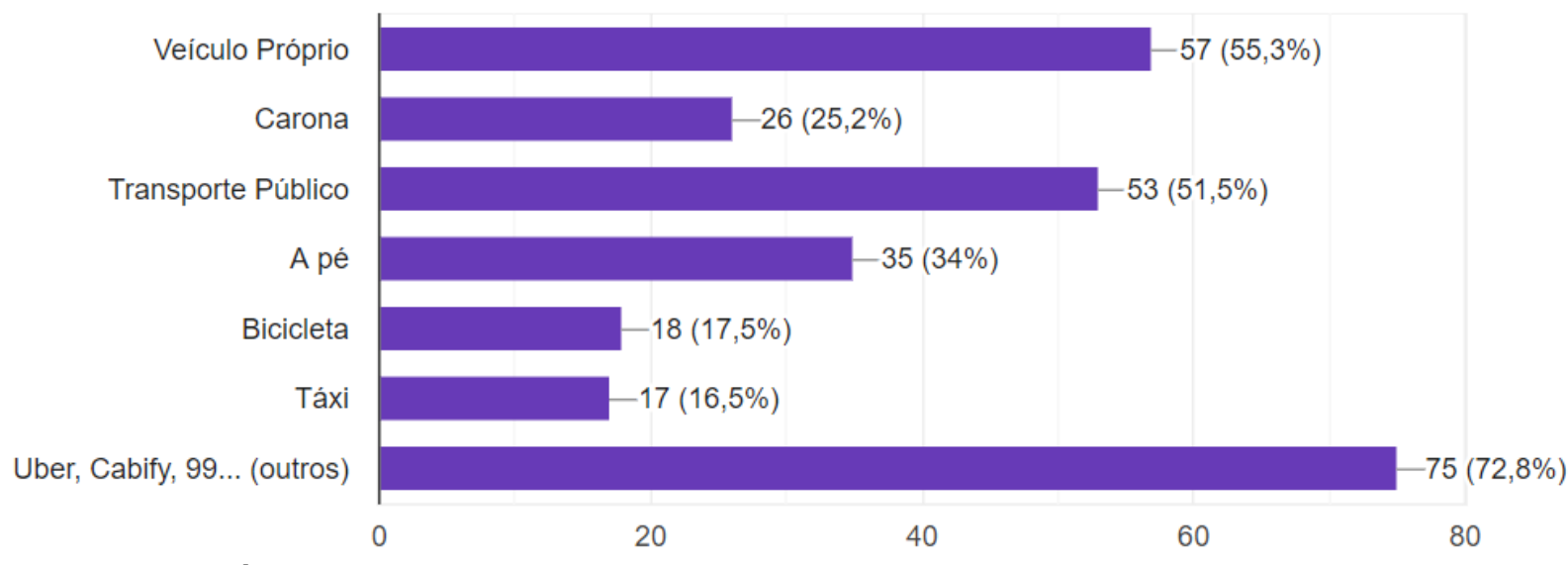

Gráfico 5: Principais meios de transportes utilizados (FONTE: Google Forms)

Dentre os aplicativos para transportes que mais são utilizados pela amostra, os principais aferidos nas respostas foram: com 98\% de resposta dos entrevistados os aplicativos de motorista particular foram a maioria e em segundo lugar com 15,5\% ficaram os aplicativos para uso de bicicletas. Apenas 3,9\% dos entrevistados não fazem uso de aplicativos para transportes. Isso indica a grande adesão e uso dos transportes por aplicativo e principalmente dos serviços de motoristas privados nessa amostra. Seguem os resultados no gráfico abaixo. Nessa questão, os entrevistados tinham a opção de selecionar uma ou mais respostas. 


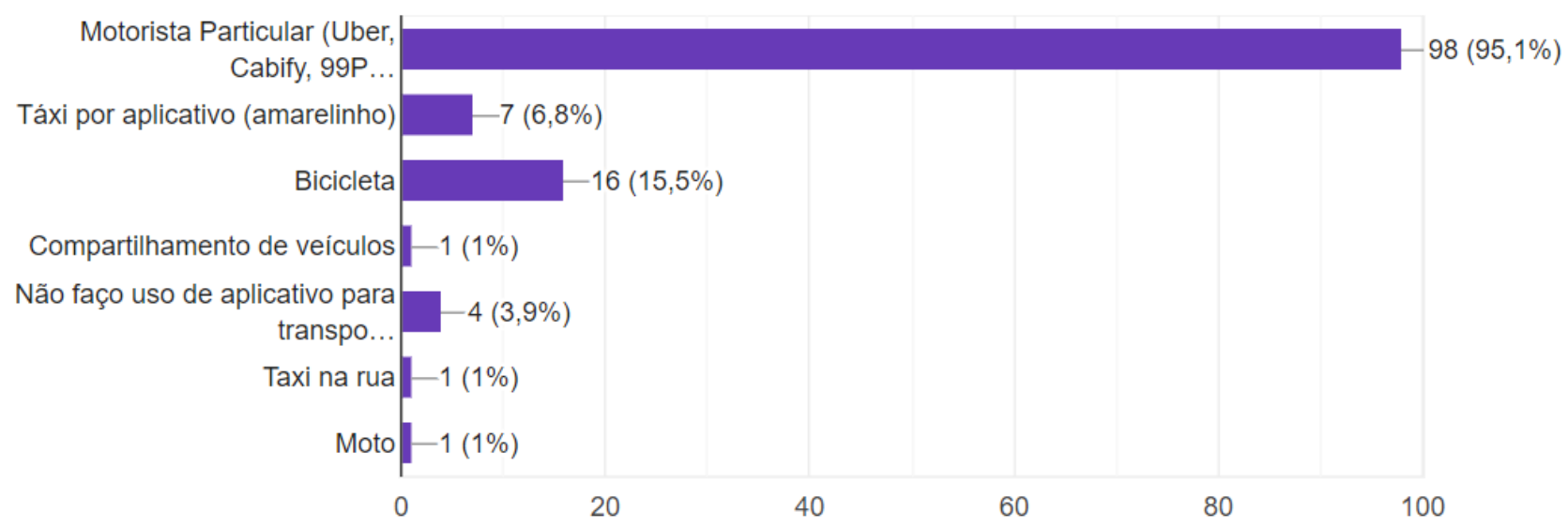

Gráfico 6: Principais aplicativos de transportes utilizados (FONTE: Google Forms)

Nesta próxima questão verificou-se a frequência de uso da amostra em relação aos transportes particulares por aplicativos com motoristas. Analisamos que a grande maioria faz uso deste transporte de 1 a 2 vezes por semana ou ocasionalmente. Com essas informações conseguiu-se entender que muitos utilizam esse meio de transporte de forma constante e em ocasiões que não queiram usar o seu carro próprio ou transporte público.

Essa escolha entre os meios de transporte disponíveis é principalmente feita pela motivação que é ativada para satisfazer as necessidades utilitárias de cada indivíduo, que segundo Solomon (2002) é o desejo de obter alguma melhoria prática ou funcional. Neste caso foi o transporte de um local ao outro. O modo como as pessoas se locomovem está diretamente ligado à sua evolução cotidiana e os benefícios dos meios disponíveis visto por cada indivíduo. 


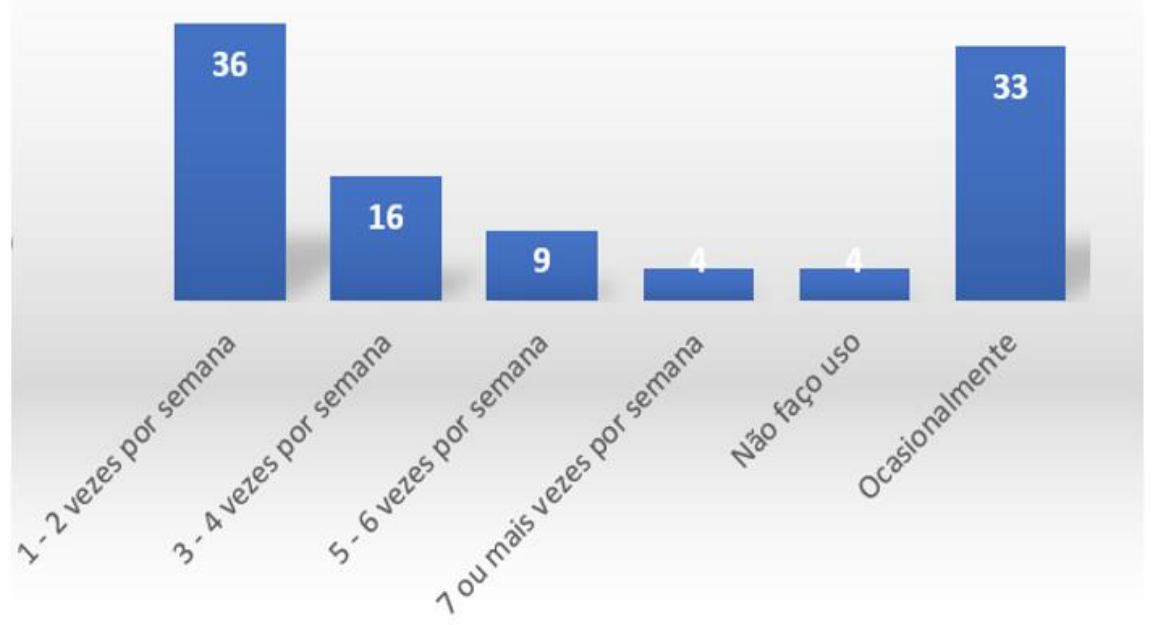

Gráfico 7: Frequência de uso de aplicativos com motorista particular (FONTE: Google Forms)

Perante a mesma questão feita acima, agora em relação aos táxis captados aleatoriamente na rua. Em sua grande maioria, com $48 \%$ dos entrevistados, faz uso do táxi somente em certas ocasiões ou não fazem uso, com 43\%. Esse resultado demonstra que as pessoas tendem a usar táxis apenas em momentos específicos como podemos aferir no Gráfico 7 a seguir.

A amostra entende como preferência por táxis nos quesitos rapidez para 0 embarque com $79 \%$ e experiência do motorista com 25\%. Enquanto que para os aplicativos, os respondentes viram que a rapidez para o embarque não é o maior benefício, pois obteve apenas $31 \%$ de respostas e a experiência do motorista apenas $9 \%$ de respostas nos aplicativos. Os respondentes optam pelo uso do táxi de rua em situações que necessitam de mais agilidade para o embarque, e percebem que 0 motorista desse modelo possui mais experiência na condução do veículo. Podemos verificar os quesitos acima nos gráficos 8 e 9 a seguir.

Os pontos que mais atendem os entrevistados no uso de aplicativos de transporte foram: o melhor preço da corrida com $80 \%$, a facilidade de pagamento com $77 \%$ e a segurança do transporte com $56 \%$. Entre eles, nos táxis foram respectivamente $3 \%, 3 \%$, $17 \%$. Com esses pontos de qualidade dos aplicativos de transportes por veículos com motoristas verifica-se, em conjunto com o gráfico 4, que os pontos, principalmente de melhor preço $\mathrm{R} \$$ da corrida e facilidade de pagamento fazem com que o consumidor 
utilize mais os transportes por aplicativo como Uber e Cabify do que táxis pegos na rua sinalizando com um gesto com as mãos.

De acordo com Solomon (2002) em relação aos filtros perceptivos, os consumidores tendem a reutilizar produtos ou serviços que foram obtidas percepções positivas. Dessa forma, pode-se identificar que os consumidores têm mais hábitos no uso de aplicativos em seu dia a dia, e procuram sempre o meio que apresenta a maior facilidade ao acesso.

\section{9}

1 - 2 vezes por semana

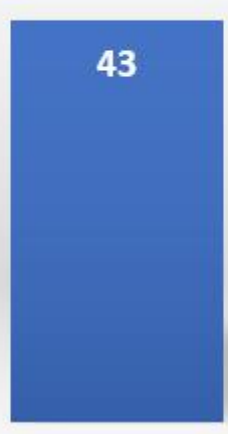

Não faço uso

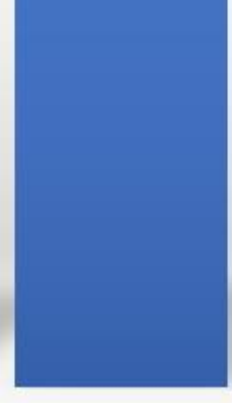

Ocasionalmente

Gráfico 8: Frequência de uso de táxis (FONTE: Google Forms) 


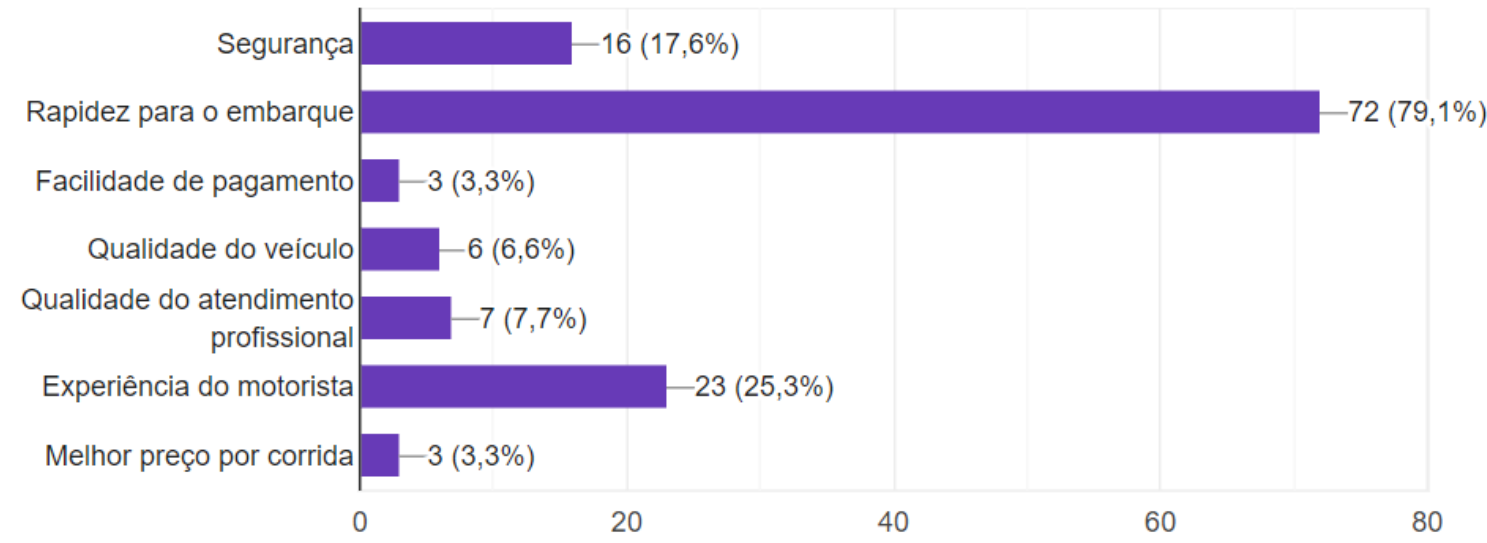

Gráfico 9: Fatores positivos no uso de táxis (FONTE: Google Forms)

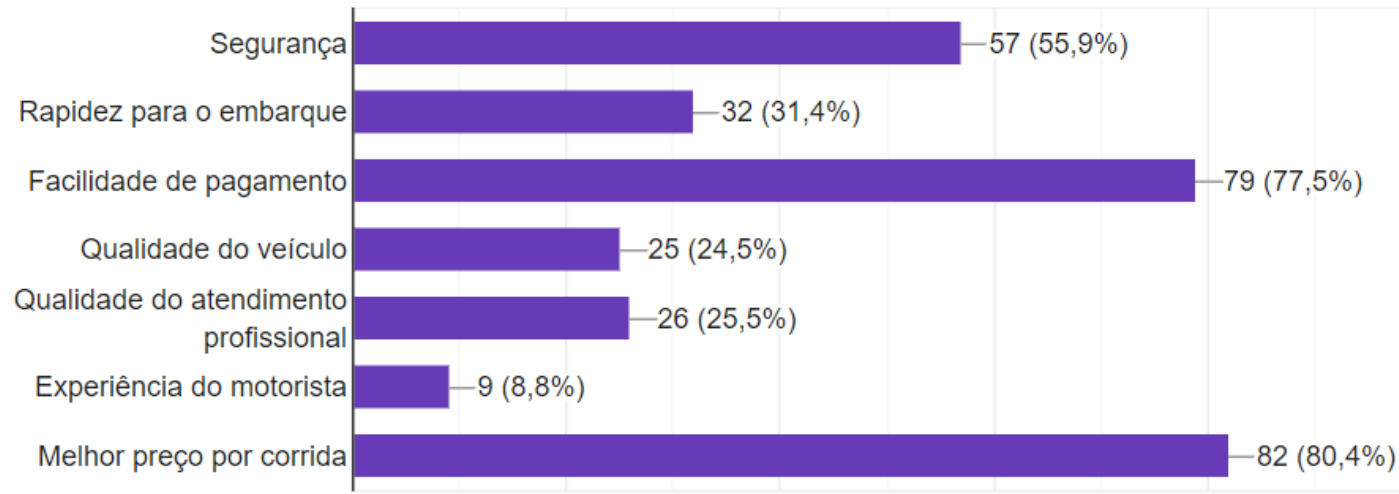

Gráfico 10: Fatores positivos no uso de transporte por meio de aplicativos (FONTE: Google Forms)

O gráfico 8 demonstra que a grande maioria da amostra utiliza táxi somente em ocasiões específicas. Pelo Gráfico 9, foram identificados os motivos que levam os entrevistados a utilizarem o táxi de rua. No caso a falta de bateria no celular obteve a maior taxa de resposta, 56,8\% dizem deixar de utilizar aplicativos para transporte e optam pelo táxi de rua, pois com o celular descarregado não é possível chamar um transporte pelo aplicativo no celular. Em momentos de pressa os $53,7 \%$ dos 
entrevistados dizem também ser um dos maiores motivos para utilizarem táxis, podendo confirmar pelo gráfico 9 que demonstra os pontos que mais são tendidos pelo uso do táxi aos respondentes. Foi necessária esta pergunta para reforçar os pontos de força de uso do táxi, assim conseguindo entender melhor quando é feito o uso do táxi ao invés de um aplicativo.

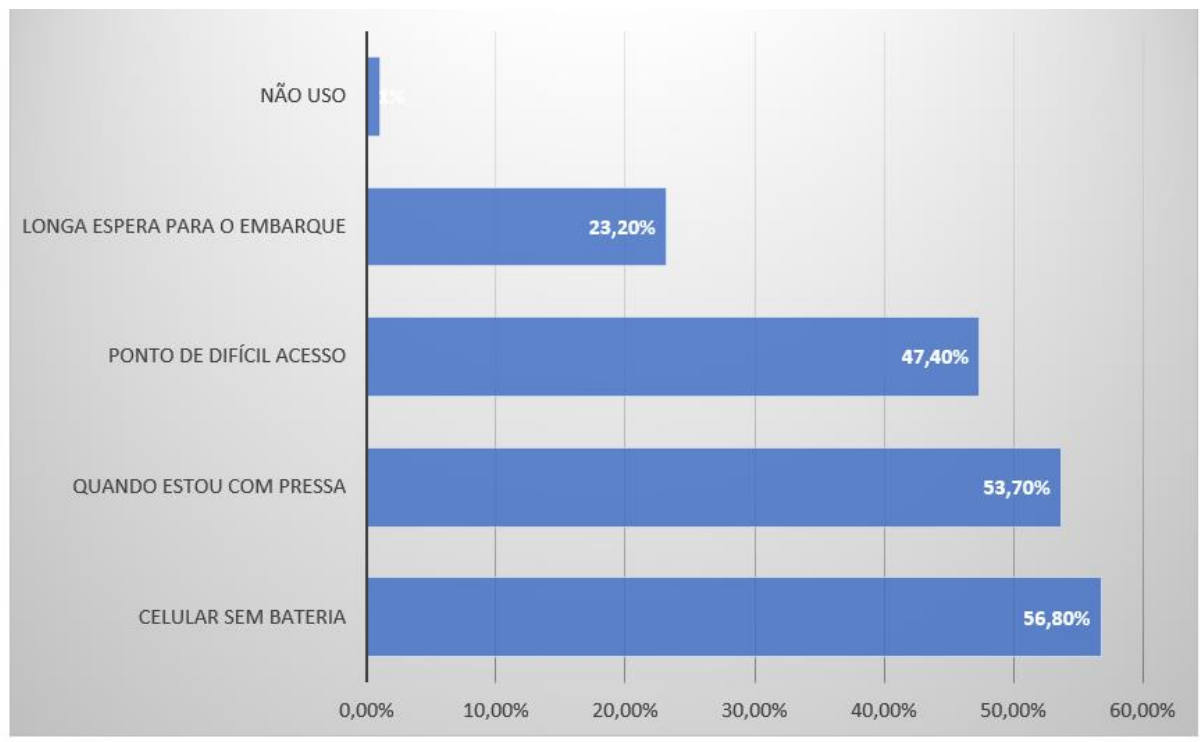

Gráfico 11: Motivos que te levam a usar táxi (FONTE: Google Forms) 
Nesta próxima seção foram feitas seis perguntas para o entrevistado fazer a escolha entre táxi, aplicativo ou não uso nenhuma das opções acima. Em relação aos seguintes pontos que indicam a preferência na qualidade do serviço entre ambos: melhor preço ao cliente, facilidade de pagamento, qualidade do veículo, qualidade do atendimento profissional, rapidez para o embarque e segurança. O respondente somente poderia fazer uma escolha por questão. Vide o gráfico 12 na página 22.

As primeiras duas perguntas, que se diziam a respeito do melhor preço ao cliente e facilidade de pagamento, deixaram a escolha do táxi quase nula. A grande maioria, com quase $97 \%$ de escolha em ambas as questões, foram para os aplicativos de transporte com veículos. Isso pode ser dar por efeito da teoria da expectativa, dita por Solomon (2002), levando em questão a transferência de conhecimento sobre um produto e seus melhores benefícios pelo efeito boca a boca e pelos meios de comunicação presentes. Os consumidores sempre procuram o melhor custo benefício para nesse caso o transporte entre dois pontos. Vide o gráfico 12 a seguir.

Em relação a qualidade do veículo, a percepção pela amostra foi de maior qualidade com $62 \%$, táxis com $17 \%$ e nenhuma opção com $21 \%$. Apesar dos dados serem favoráveis aos aplicativos, uma parte significativa (21\%) declarou que não está satisfeita com a qualidade de ambos os veículos disponíveis. Demonstrando que ainda existe uma melhora a ser feita. De acordo com os autores Schiffman e Kanuk (2000, p. 125): "os consumidores frequentemente julgam a qualidade de um produto com base em uma variedade de sinais informacionais que associam ao produto". Vide o gráfico 12 a seguir.

As próximas questões lidaram com a percepção sobre o serviço, no qual pode variar muito devido a fatores intangíveis, onde a influência pode vir do humor de cada partido, seja o cliente ou prestador de serviço. Para os serviços, existem quatro fatores que influenciam sobre a percepção do consumidor, são eles a seguir: intangibilidade, variabilidade, perecibilidade e simultaneidade. Tendo esses fatores em vista, o consumidor procura uma maneira de conseguir avaliar esse serviço. Assim os usuários contam com sinais extrínsecos para comparar e avaliar a qualidade de um serviço. Com a confiabilidade, tangibilidade, atendimento do profissional e segurança. (Schiffman e Kanuk, 2000).

O profissional tem um papel crucial no atendimento em ambos os casos (taxí ou aplicativos), pois é o primeiro contato físico entre pessoas e a segurança do passageiro está nas mãos da condução do motorista. De acordo com a pesquisa feita, $70,6 \%$ preferem a qualidade de atendimento do profissional vinculado ao um aplicativo de celular e $12,7 \%$ optam por escolher o atendimento em táxis. Foi um bom resultado para 
os aplicativos, mas ainda $16,7 \%$ da amostra diz que não opta por nenhum dos dois (táxis ou aplicativos), demonstrando que uma parte pode não estar satisfeita com ambos os serviços, dando espaço para melhorias ou novos entrantes nesse segmento de mercado. A próxima questão seria em relação a rapidez para o embarque, e como visto e analisado no gráfico 8 , foi para confirmar a teoria de que as pessoas utilizam táxi quando estão na rua com pressa, assim, vamos a próxima questão. Um dos fatores que faz os consumidores da amostra optarem pelo uso de transporte em veículos por aplicativos é a segurança dos mesmos. $80,4 \%$ da mostra percebe como mais seguro utilizar os aplicativos ao invés de táxis com apenas $10,8 \%$. Visto que a população estava precisando de um transporte mais seguro, com maior qualidade, e melhor atendimento foi o momento de avanço da preferência por aplicativo que obtiveram essa excelente percepção de mercado. O consumidor se sente mais seguro, com melhor meio de pagamento e um custo por corrida percebido como inferior aos táxis. Os índices de assaltos principalmente no estado do Rio de Janeiro são graves, em 2017 os valores subiram 10,3\% em relação a 2016, totalizando 230.450 roubos em 2017 o que corresponde 1.378 ocorrências a cada 100 mil habitantes. Esse constante aumento nos índices de violência deixa a população cada vez mais procurando meios de transportes seguros e que possam ter controle sobre o trajeto. Pode ser observado no gráfico 12 a seguir, que a segurança foi um dos principais pontos positivos em relação ao transporte com motoristas por aplicativos.

As principais vantagens competitivas percebidas pelos respondentes do modelo de transporte em veículos particulares foram o melhor preço ao consumidor, a facilidade de pagamento, o atendimento profissional e a segurança. Novamente para o uso dos táxis o único ponto de qualidade percebido como melhor foi no quesito rapidez para o embarque $(59,8 \%)$. Vide o gráfico 12 a seguir.

Como o consumidor obteve uma experiência de serviço melhor utilizando os aplicativos, de acordo com o processo decisório definido por Blackwell, Engel \& Miniard (2008) que tem como base sete etapas, são elas: reconhecimento da necessidade, busca de informações, avaliação de alternativas pré-compra, compra, consumo, avaliação pós consumo e descarte.

O consumidor reconhece a necessidade de precisar se locomover para algum local, por referências de amigos ou promoções em redes sociais ele busca e avalia as alternativas que seriam os aplicativos disponíveis, chama o motorista pelo aplicativo fazendo a compra, faz o consumo durante a corrida até o seu destino e após o consumo o ciente pode avaliar a sua experiência. A partir desse momento o consumidor pode 
fazer uso da teoria de heurística, que torna a tomada de decisões para a compra de um produto/serviço mais acelerada ou fáceis. (Solomon, 2002).

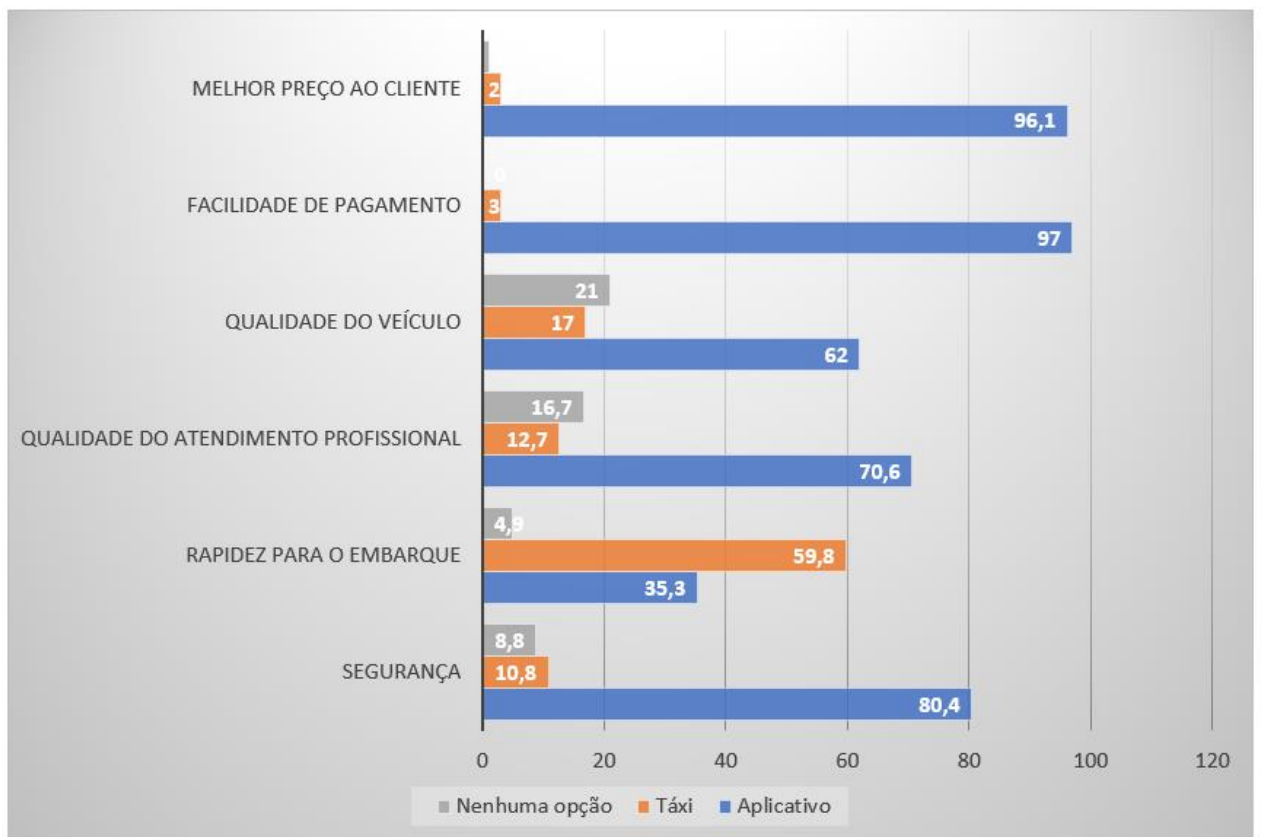

Gráfico 12: Comparação dos serviços oferecidos por táxis e aplicativos (FONTE: Google Forms)

As duas últimas questões pediam ao consumidor para avaliar com uma nota de 1 a 5 em relação ao seu grau de satisfação com os aplicativos de transporte particular e táxis, para determinar a percepção de satisfação geral entre os dois meios de transportes concorrentes. Sendo a nota 1 o cliente estaria insatisfeito com o uso do meio de transporte e 5 estaria satisfeito. Vide gráfico 13 a seguir.

A experiência de consumo pode criar um reforço positivo, negativo ou de punição no consumidor. Os reforços positivos no consumo ocorrem quando o cliente recebe um estímulo por utilizar o serviço ou produto, como a satisfação ou reconhecimento por outros. Neste estudo, a satisfação ocorre quando o consumidor consegue utilizar um meio mais barato de transporte, que seriam pelos aplicativos ao invés dos táxis, com maior sensação de segurança, pois o consumidor recebe a placa do veículo e quem é o motorista antes de embarcar, e um melhor atendimento com motoristas mais educados.

Nos dados demonstrados pelo gráfico 13, pode-se verificar que as notas de satisfação pelo serviço de transportes ficaram significantemente mais altas para o uso de aplicativos ao invés de táxis. Nessa questão, a nota 1 o usuário se diz pouco satisfeito e crescendo na escala, a nota 5 , seria muito satisfeito. Os maiores percentuais para os 
aplicativos ficaram concentrados entre as notas 4 e 5, e para a satisfação de uso dos táxis ficaram entre as notas 3 e 4. De acordo com Solomon (2002) o consumidor tende a escolher o produto ou serviço que obtiver a maior soma de atributos positivos em sua percepção.

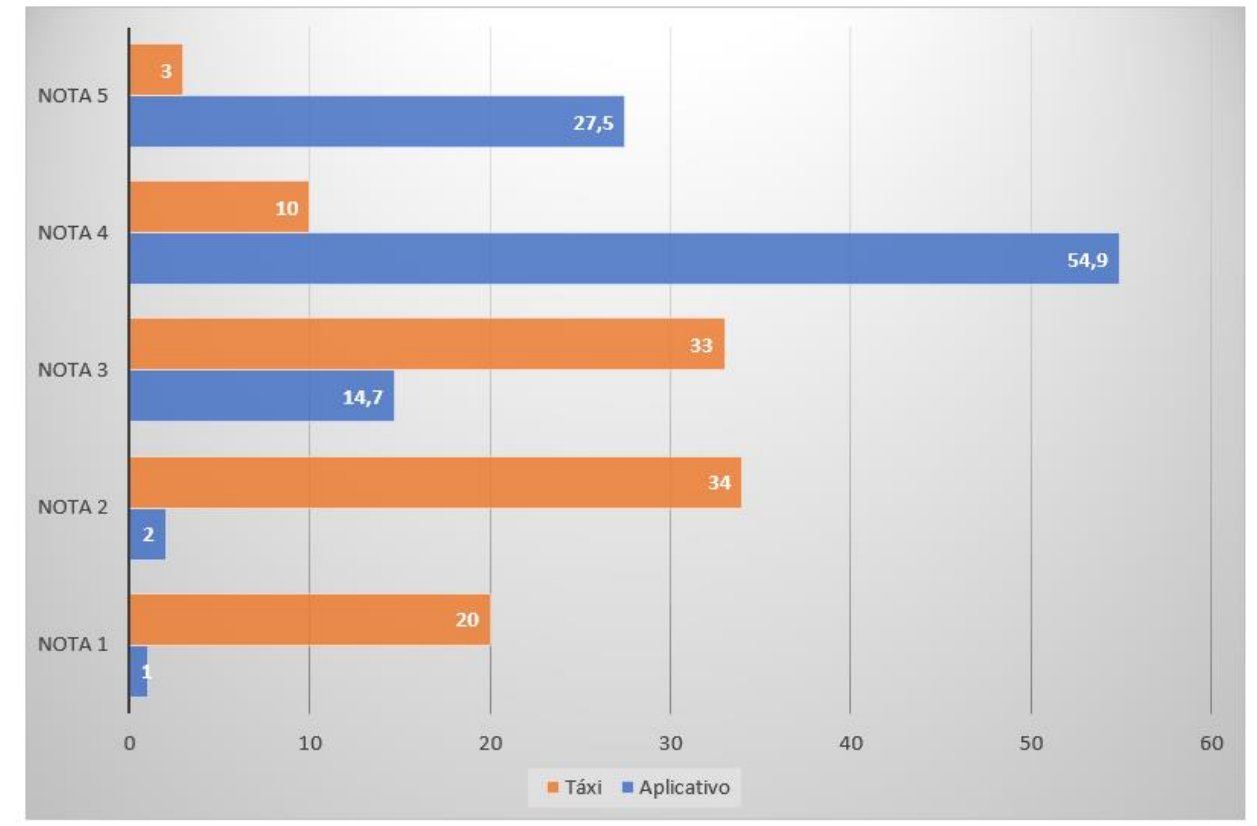

Gráfico 13: Grau de satisfação do consumidor (FONTE: Google Forms)

Ficou claro que a percepção do consumidor hoje é mais positiva pelo uso dos aplicativos de veículos como os principais atualmente no mercado Uber, Cabify e 99taxi. No ano de 2017 a Uber liderou o mercado com 10 milhões de corridas por mês, depois a 99 com 1,5 milhões de corridas por mês e em terceiro a Cabify com em torno de 900 mil corridas por mês.
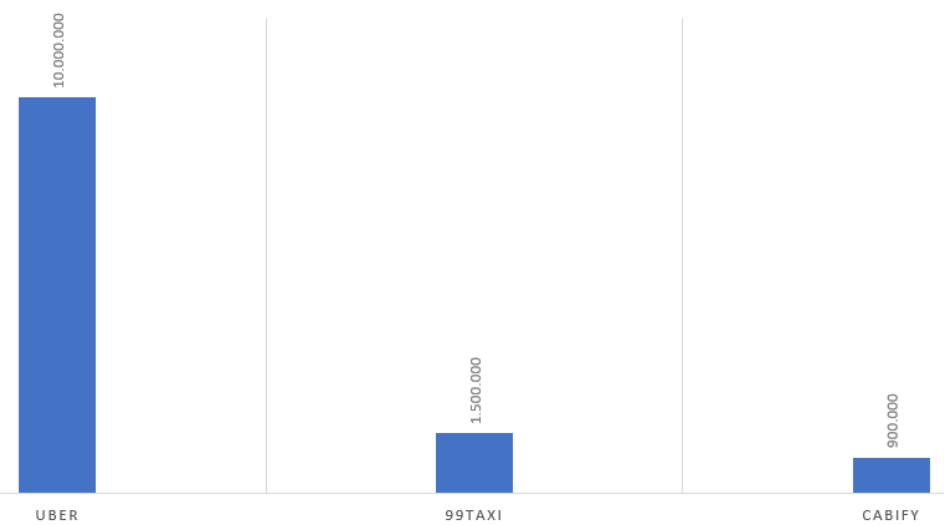

Gráfico 14: Número de corridas por mês (FONTE: Exame, 2017) 


\section{Conclusão}

Este trabalho pretendeu analisar a percepção dos consumidores comparando os meios de transportes utilizando táxis e aplicativos móveis. O principal foco foi entender porque a adesão atual é tão grande sobre o uso dos aplicativos pelos consumidores, e se os usuários ainda preferem adquirir o serviço pelo modelo de aplicativo. Tendo em vista o que motivaria o consumidor a optar por ambos os casos estudados e a percepção de cada entrevistado sobre os dois meios, táxis e aplicativos.

Toda a análise foi baseada e aprofundada nos estudos feitos pelos autores: nos assuntos percepção do consumidor, motivação de consumo, processo de tomada de decisão, comportamento do consumidor. Os autores utilizados foram: Leon G. Schiffman (2000) e Leslie Lazar Kanuk (2000), Michael R. Solomon (2002) e Blackwell, Engel \& Miniard (2008).

Nesta pesquisa foram aferidos 102 questionários de respostas, utilizando a plataforma online do Googleforms onde foi criado e distribuindo pelo link criado nos meios de comunicação Whatsapp e Facebook. Todos os dados foram criados através da plataforma do próprio Googleforms e transferido para o Excel para a criação dos gráficos.

O problema proposto foi compreender o porquê da forte adesão ao uso dos aplicativos para transporte com motoristas pelos consumidores. Após verificar e analisar os dados resultantes da pesquisa, pode-se concluir que existem três principais pontos que diferenciam o meio de serviço executado pelos aplicativos comparados ao que os taxistas veem utilizando. O melhor preço por corrida, a facilidade de pagamento e a segurança percebida pelo consumidor foram os principais fatores identificados que fazem com que o serviço prestado pelas empresas de aplicativos terem essa grande adesão. A falta de burocracia e baixos custos para se tornar um motorista de aplicativo fez com que muitos desempregados e pessoas com a necessidade de mais uma renda mensal aderissem para serem prestadores de serviço dos aplicativos, seja Uber, 99, Cabify ou outros. Por esses motivos os aplicativos conquistaram tanta adesão de consumo, fazendo o meio de transporte por táxi captado na rua parecer antiquado e como um serviço inferior prestado percebido pelos usuários. Como todo produto no mercado, é sempre necessário se inovar, se adequar ao ambiente externo, aparentemente os táxis captados na rua ficaram para trás e são na maior parte utilizados 
apenas quando o consumidor se encontra sem bateria ou quando está com pressa na rua.

Com o valor da corrida por um menor valor e o serviço percebido de maior qualidade os aplicativos são a preferência dos usuários e o consumidor tende a fazer uso dos mesmos diversas vezes por semana em sua rotina, não somente ocasionalmente.

Como sugestão para melhorar a adesão ao uso de táxis de rua seria reduzir os valores das tarifas aplicadas para ficarem com preços mais competitivos em relação aos aplicativos. Facilitar o pagamento garantido sempre uma maquina de cartão para todas as bandeiras no veículo.

Para os aplicativos seria interessante reforçarem os padrões de qualidade tanto dos motoristas oferecendo algum treinamento e inspeção dos seus veículos com mais frequência. Assim garantindo a continuidade da conquista de novos consumidores. Uma maneira para aumentar seu marketshare ${ }^{3}$ seria tentar ter pontos de rua específicos em locais de grande circulação para justamente captar os clientes com mais pressa.

Para uma continuação da pesquisa, pode ser comparado os principais pontos de qualidade que atendem o consumidor entre as empresas de aplicativos para transporte e novas tendências para o futuro.

${ }^{3}$ O termo "marketshare" tem como significado a fração de participação de uma empresa no mercado, podendo ser pelas vendas de um determinado produto ou sua relevância de faturamento no segmento. 


\section{Referências Bibliográficas}

BLACKWELL, R. D.; MINIARD, P. W.; ENGEL, J. F. Comportamento do consumidor. 9aㅗ ed. São Paulo: Cengage Learning, 2008.

DRIVERMACHINE. O Mercado de Corrida por Apps no Brasil. Disponível em:http://drivermachine.com.br/o-mercado-de-corrida-por-apps-no-brasil/.Acesso em: 8 nov. 2018.

DUSI, Luiza. O uso de aplicativos para smartphone no transporte individual: 99taxi e uber. 2016. 104 pág. (Departamento de engenharia cívil) - Universidade de Brasília, Brasília, 2016.

ESTADAO. Chegada do uber ao brasil reduziu mais da metade das corridas de aplicativos de táxi, concluiu estudo. Disponível em: $<$ https://economia.estadao.com.br/noticias/geral,chegada-do-uber-ao-brasilreduziu-mais-da-metade-das-corridas-de-aplicativos-de-taxi-concluiestudo,70002265737>. Acesso em: 23 out. 2018.

GIL, A. C. Como elaborar projetos de pesquisa. São Paulo: Atlas, 2002.

GAZETA. Estatística do caos: violência no Rio é a que mais aumenta. Disponível em: $\quad<$ https://www.gazetaonline.com.br/noticias/policia/2018/02/estatistica-docaos-violencia-no-rio-e-a-que-mais-aumenta-1014120694.html>. Acesso em: 17 out. 2018.

SCHIFFMAN, LEON G; KANUK, LESLIE. LAZAR Comportamento do consumidor. Tradução de Dalton Conde de Alencar. 9ª Ed. Rio de Janeiro: LTC, 2009.

SOLOMON, MICHAEL R. Comportamento do Consumidor: Comprando, possuindo e sendo. 11ª . Edição. Porto Alegre: Bookman, 2016. 
VALOR. Para Cabify, Brasil já é o maior mercado mundial. Disponível em: $<$ https://www.valor.com.br/empresas/4993674/para-cabify-brasil-ja-e-maiormercado-mundial>. Acesso em: 17 out. 2018. 


\section{Anexo}

\section{Qual a sua faixa etária?}

Escolha apenas uma opção

17 anos ou menos

18 - 25 anos

26 - 33 anos

$34-41$ anos

42 - 49 anos

$50-57$ anos

$58-65$ anos

66 anos ou mais

\section{Qual seu Gênero ?}

Escolha apenas uma opção

*

Feminino

Masculino

Qual a sua Renda Mensal ?

Escolha apenas uma opção

Menor que $\mathrm{R} \$ 954,00$

Entre $\mathrm{R} \$ 955$ e $\mathrm{R} \$ 1.908,00$

Entre $\mathrm{R} \$ 1.909,00$ e $\mathrm{R} \$ 3.817,00$

Entre $R \$ 3.818,00$ e $R \$ 5.725,00$

Entre $R \$ 5.726,00$ e $R \$ 7.633,00$

Entre $\mathrm{R} \$ 7.634$ e $\mathrm{R} \$ 9.541,00$

Mais de $\mathrm{R} \$ 9.542,00$

Qual(is) meio(s) de transporte você mais faz uso?

Escolha uma ou mais opções

Veículo Próprio

Carona

Transporte Público

A pé

Bicicleta

Táxi

Uber, Cabify, 99... (outros)

Outro:

Qual(is) aplicativo(s) para transporte você utiliza ?

Escolha uma ou mais opções 
Motorista Particular (Uber, Cabify, 99Pop...)

Táxi por aplicativo (amarelinho)

Bicicleta

Compartilhamento de veículos

Não faço uso de aplicativo para transporte

Outro:

\section{Qual a sua frequência de uso do transporte particular por APLICATIVO ?}

Escolha apenas uma opção

Ocasionalmente

1 - 2 vezes por semana

3 - 4 vezes por semana

5 - 6 vezes por semana

7 ou mais vezes por semana

Não faço uso

Qual a sua frequência de uso do TÁXI de rua ?

Escolha apenas uma opção

Ocasionalmente

1 - 2 vezes por semana

3 - 4 vezes por semana

5 - 6 vezes por semana

7 ou mais vezes por semana

Não faço uso

Qual(is) o(s) ponto(s) que mais lhe atende $(\mathrm{m})$ no uso do transporte por APLICATIVO ?

Escolha uma ou mais opções

Segurança

Rapidez para o embarque

Facilidade de pagamento

Qualidade do veículo

Qualidade do atendimento profissional

Experiência do motorista

Melhor preço por corrida

Qual(is) o(s) ponto(s) que mais lhe atende $(\mathrm{m})$ no uso do TÁXI de rua ?

Escolha uma ou mais opções

Segurança

Rapidez para o embarque

Facilidade de pagamento

Qualidade do veículo

Qualidade do atendimento profissional

Experiência do motorista

Melhor preço por corrida

Qual(is) motivo(s) te leva(m) a utilizar o TÁXI de rua?

Escolha uma ou mais opções

Quando meu celular está sem bateria

Ponto de difícil acesso

Quando estou com pressa

Longo tempo de espera para o embarque

Outro:

Dentre os pontos de qualidade abaixo, qual meio mais lhe atende? 
Escolha apenas uma opção

Segurança

Aplicativo

Táxi de rua

Nenhuma dos opções acima

Rapidez para o Embarque

Aplicativo

Táxi de rua

Nenhuma dos opções acima

Qualidade do Profissional

Aplicativo

Táxi de rua

Nenhuma dos opções acima

Qualidade do Veículo

Aplicativo

Táxi de rua

Nenhuma dos opções acima

Facilidade de Pagamento

Aplicativo

Táxi de rua

Nenhuma dos opções acima

Melhor Preço ao Cliente

Aplicativo

Táxi de rua

Nenhuma dos opções acima

Qual o seu grau de satisfação com o uso do transporte particular por aplicativo ?

Escolha apenas um valor

Insatisfeito

1

2

3

4

5

Satisfeito

Qual o seu grau de satisfação com o uso do táxi de rua ?

Escolha apenas um valor

1
2
3
4
5

Insatisfeito

Satisfeito

\section{MUITO OBRIGADO PELA SUA PARTICIPAÇÃO!}


